\title{
Sediment supply as a driver of river meandering and floodplain evolution in the Amazon Basin
}

\author{
José Antonio Constantine ${ }^{1 \star}$, Thomas Dunne ${ }^{2,3 \star}$, Joshua Ahmed ${ }^{1}$, Carl Legleiter ${ }^{4}$ and Eli D. Lazarus ${ }^{1}$
}

The role of externally imposed sediment supplies on the evolution of meandering rivers and their floodplains is poorly understood, despite analytical advances in our physical understanding of river meandering ${ }^{1,2}$. The Amazon river basin hosts tributaries that are largely unaffected by engineering controls and hold a range of sediment loads, allowing us to explore the influence that sediment supply has on river evolution. Here we calculate average annual rates of meander migration within 20 reaches in the Amazon Basin from Landsat imagery spanning 1985-2013. We find that rivers with high sediment loads experience annual migration rates that are higher than those of rivers with lower sediment loads. Meander cutoff also occurs more frequently along rivers with higher sediment loads. Differences in meander migration and cutoff rates between the study reaches are not explained by differences in channel slope or river discharge. Because faster meander migration and higher cutoff rates lead to increased sediment-storage space in the resulting oxbows, we suggest that sediment supply modulates the reshaping of floodplain environments by meandering rivers. We conclude that imposed sediment loads influence planform changes in lowland rivers across the Amazon.

Decades of fluvial research have yielded physical insight into river behaviours associated with various channel patterns, from planform controls on meander migration, to mechanisms responsible for dispersing sediment into the floodplain ${ }^{2,3}$ and the in-channel dynamics that produce sediment supply from local bank erosion ${ }^{4}$. By contrast, the role of externally imposed sediment supplies in channel planform dynamics-that is, when sediment supplies are an imposed environmental variable to which the channel planform must adjust-remains poorly understood. External sources of sediment may derive from mountain building, glacial and other climatic changes, volcanism, and land uses that accelerate landscape-scale soil loss. They may also be interrupted by water resource developments such as the large reservoirs under consideration for many Amazonian tributaries ${ }^{5}$.

The Amazon Basin remains a unique opportunity to assess the role of externally imposed sediment supplies in river evolution because of the generally undeveloped nature of its fluvial environments and the range of sediment supplies in its various tributary basins. Rivers within the $6.9 \times 10^{6} \mathrm{~km}^{2}$ basin are generally free to modify their forms, and they drain distinct physiographic provinces, each of which supplies sediment to the channel network at different rates ${ }^{6,7}$. Rivers draining the highly erodible Andean Cordillera yield the greatest amount of sediment to the Amazon lowlands, on the order of $100 \mathrm{Mt}$ of suspended material per river each year ${ }^{8-10}$. Rivers with headwaters draining the fine-grained Neogene sedimentary rocks of the Central Amazon Trough yield an order of magnitude less sediment per river each year', and those that drain the Guiana Shield to the north and the Brazil Shield to the south of the Trough yield the least ${ }^{7}$.

As sedimentary deposits attached to the inner banks (convex relative to the channel centreline) of meander bends, point bars seem to be the link between changes in externally imposed sediment supplies and adjustments in river behaviour. Modern theory attributes the meandering behaviour of alluvial rivers to instabilities in river flow ${ }^{11}$ that arise either inherently ${ }^{12}$ or from disruption of the flow field by bedforms ${ }^{13}$. Recent lab experiments suggest that this latter influence may not be ubiquitous ${ }^{14}$, but the capacity for point bars to promote meandering by altering the flow field ${ }^{15}$ has been observed both in the field ${ }^{16}$ and the laboratory ${ }^{17}$. A view of the Rio Mamoré, flowing through the Andean foreland basin of Bolivia, offers an illustration. The Rio Grande, a tributary of the Rio Mamoré, drains $7.2 \times 10^{4} \mathrm{~km}^{2}$ of the Bolivian Andes and transports about $136 \mathrm{Mt} \mathrm{yr}^{-1}$ of suspended sediment as it enters the foreland basin ${ }^{10}$. The substantial sediment load of the Rio Grande has resulted in the enhanced development of point bars on the Rio Mamoré downstream of the confluence (Fig. 1a) that has instigated a nearly 1.7 -fold increase in rates of meander migration (Fig. 1b). Observations from the Sacramento River of California, USA, further

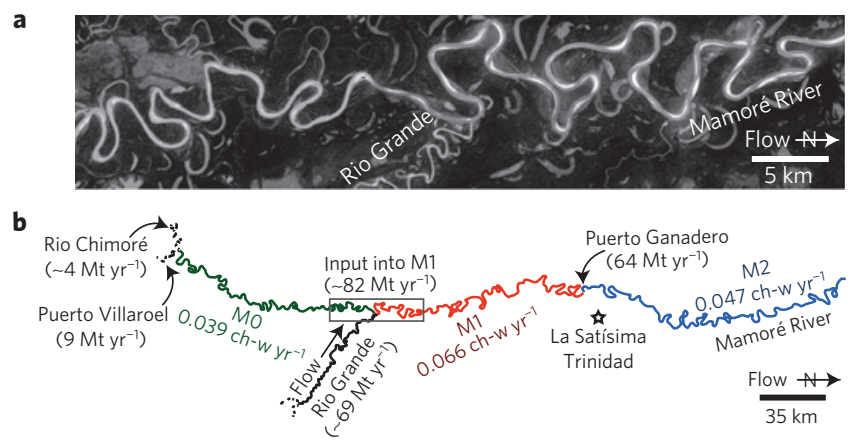

Figure 1 | Enhanced development of point bars on the Rio Mamoré downstream of the confluence with the Rio Grande. a, Landsat image from 2013 of the Rio Mamoré and its confluence with the Rio Grande, which drains the Bolivian Andes from the southeast. b. Study reaches of the Mamoré (M0, green; M1, red; M2, blue), with average annual meander migration rates provided for each (in units of channel widths per year) for the time period 1986-2010. The box shows the location of the image in a. Estimates of total suspended sediment (TSS) flux are shown in brackets. Details of TSS flux estimates can be found in the Supplementary Information.

\footnotetext{
${ }^{1}$ School of Earth and Ocean Sciences, Cardiff University, Cardiff CF10 3AT, UK, ${ }^{2}$ Bren School of Environmental Science and Management, University of California-Santa Barbara, Santa Barbara, California 93106, USA, ${ }^{3}$ Department of Earth Science, University of California-Santa Barbara, Santa Barbara, California 93106, USA, ${ }^{4}$ Department of Geography, University of Wyoming, Laramie, Wyoming 82071, USA. *e-mail: constantineja@cardiff.ac.uk; tdunne@bren.ucsb.edu
} 


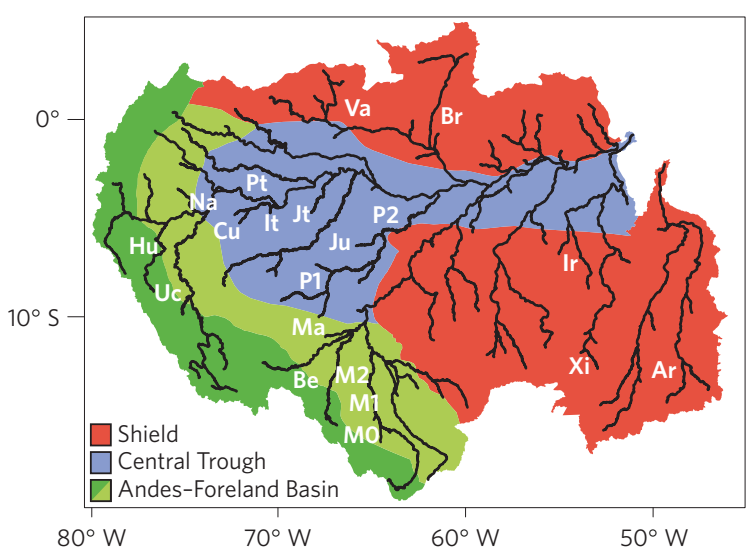

Ar, Araguaia; Va, Vaupés; Br, Branco; Ir, Iriri; Xi, Xingu; P1, Purus1;

P2, Purus2; Ju, Juruá; Jt, Jutai; It , Ituí; Cu, Curuca; Na, Nanay; Pt, Putumayo; M0, Mamoré0; M1, Mamoré1; M2, Mamoré2; Be, Beni; Uc, Ucayali; Hu, Huallaga; Ma, Madre de Díos

C

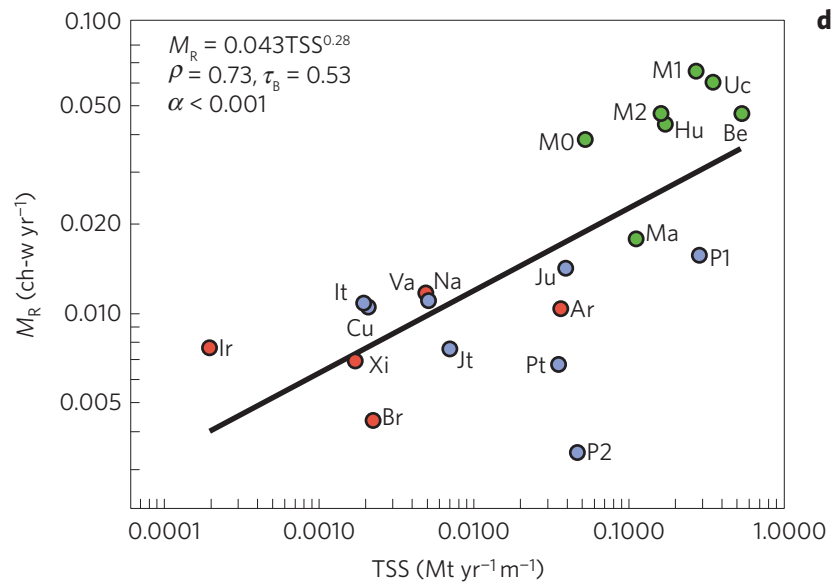

b
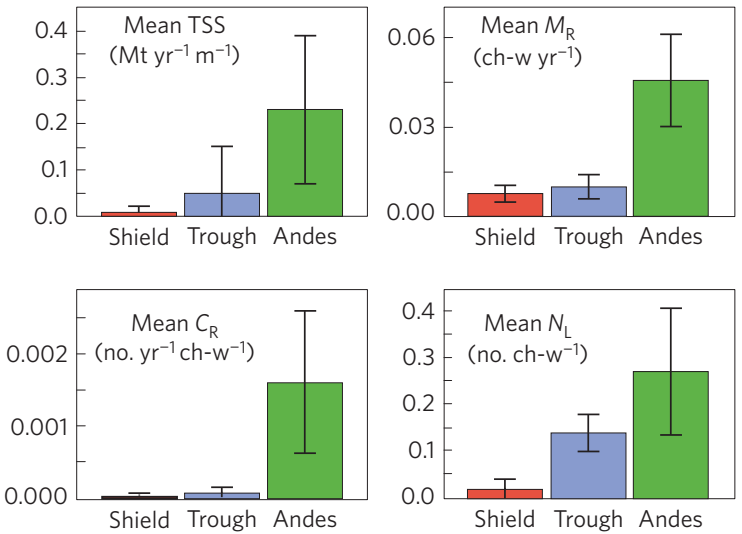

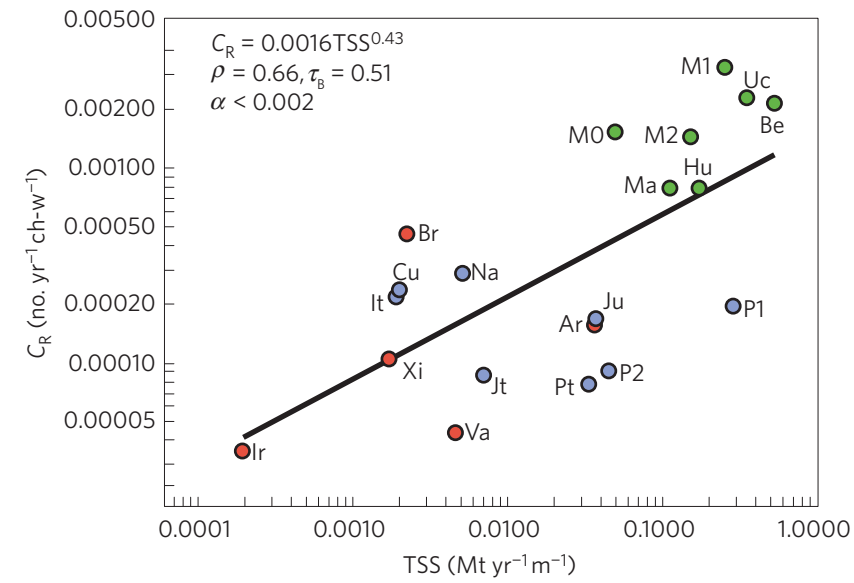

Figure $\mathbf{2}$ | Study sites, river characteristics, and sediment fluxes. a, Locations of study reaches within the physiographic provinces with reach abbreviations defined. b. Mean values for total suspended sediment (TSS) flux (megatonnes per year per metre of channel width), average annual meander migration rate $\left(M_{R}\right.$; channel widths per year), average annual meander cutoff rate $\left(C_{R}\right)$ (number per year per channel width of down-valley distance), and total number of observable oxbow lakes ( $N_{\mathrm{L}}$; number per channel width of down-valley distance). Error bars represent $\pm 1 \sigma$ about the means. $\mathbf{c}, M_{\mathrm{R}}$ plotted against TSS flux. d, $C_{R}$ plotted against TSS flux.

highlight the role of point bars in facilitating bank erosion in reaches that experience a net accumulation of bed material ${ }^{18}$.

Within a given meander, curvature and shoaling of river flow onto and over a point bar force high-momentum fluid to be advected outwards, increasing boundary shear stress along the outer (concave) riverbank and decreasing boundary shear stress over the inner-bank bar ${ }^{15}$. Elevated shear stresses near the outer bank promote the fluvial entrainment of the bank material primarily responsible for bank erosion ${ }^{19}$, and the displacement of the zone of maximum shear stress from the inner to the outer bank shifts the zones of maximum bed-material transport and bank scour accordingly ${ }^{15}$. As a result, the bar aggrades, growing laterally and vertically ${ }^{20}$ until its surface is infrequently inundated, promoting the continued advection of high-momentum fluid by increasing flow curvature and asymmetric shoaling.

To assess the importance of sediment supply in meandering river evolution, we used sequences of Landsat images for twenty reaches from across three physiographic provinces of the Amazon Basin to calculate average annual rates of meander migration and meander cutoff (Fig. 2a), which were related to reported estimates of the average annual total suspended sediment (TSS) supply to each reach. Meander migration rates $\left(M_{\mathrm{R}}\right)$ were normalized by average bankfull channel width $\left(R_{\mathrm{W}}\right)$ to account for the influence of channel size on rates of lateral shifting. Cutoff rates $\left(C_{R}\right)$ were normalized by reach valley-length, expressed in channel-width units (ch-w). TSS flux estimates were normalized by $R_{\mathrm{W}}$ to account for the ability of wider channels with greater flows to convey more sediment. We used TSS data from the most extensive and systematically collected survey of sediment supplies currently available for the Amazon Basin ${ }^{7}$. Details of values from other sources are provided in the Supplementary Information. TSS flux is the only widely (if sparsely) distributed measure of sediment supplies in the Amazon and other large river systems. It includes both sandy bed material, which is the material of bar formation, and silt-clay washload, which is transported through the channel and into floodplains without being sequestered onto bars. We used TSS as a proxy for bed-material load (including sediment transported as bed load or suspended load), which will be required until direct measurements of bed-material flux become available. Such measurements are available for only one season in a single reach of an Amazonian tributary ${ }^{21}$. For the Amazon mainstem and seven of its tributaries, it has been estimated that bedload transport rates are $<1 \%$ of total load, the sandy bed-material transport is dominated by suspension and annual suspended sand loads comprise an average of $20 \%$ of TSS for both the mainstem Amazon and its tributaries (17\% for tributaries with no or very small Andean sources) ${ }^{3}$. In our analysis, we grouped rivers according 
a

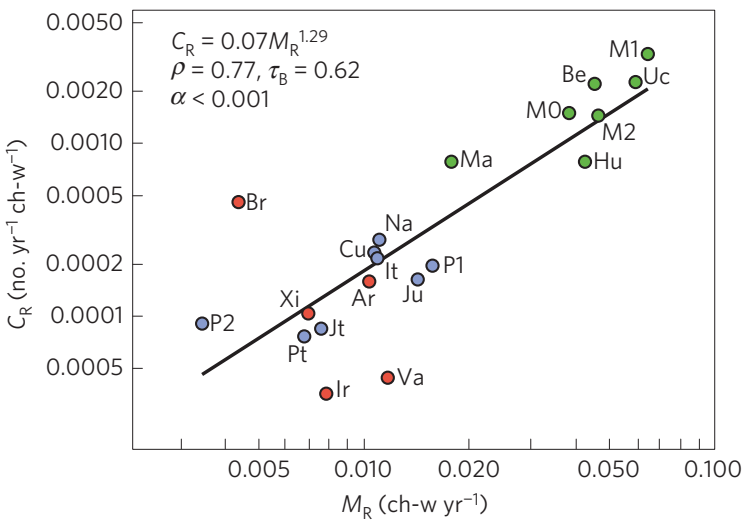

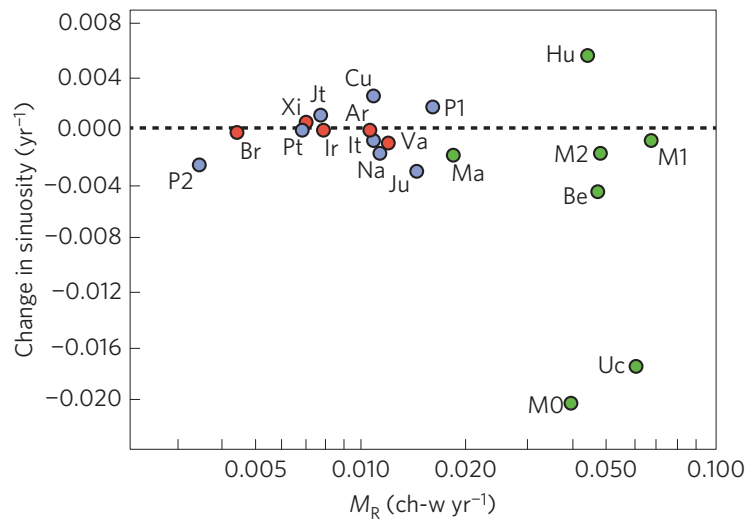

c

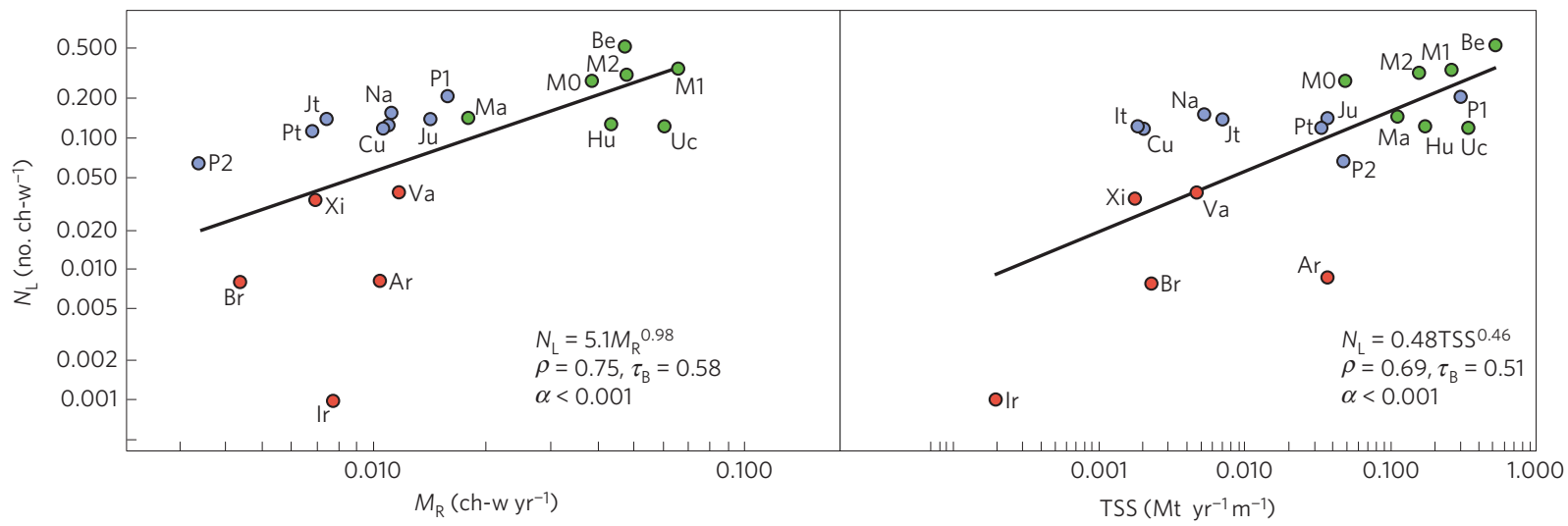

Figure 3 | Meander migration and cutoff in the maintenance of channel sinuosity. a, Average annual rate of meander cutoff $\left(C_{R}\right.$; number per year per channel-width down-valley distance) for the 20 study reaches shown in Fig. 2a plotted against average annual meander migration rate ( $M_{R}$; channel widths per year). $\mathbf{b}$, Average annual rate of change in channel sinuosity plotted against $M_{R}$ for each reach. $\mathbf{c}$, Observable oxbow lakes counted within the floodplains of the study reaches ( $N_{L}$; number per channel width of down-valley distance) plotted against $M_{R}$ and reported total suspended sediment (TSS) flux (megatonnes per year per metre of channel width).

to their dominant sediment-source regions: the Andes (AndesForeland Basin), the Central Amazon Trough, and the Guiana Shield and Brazil Shield (shields). We used two-tailed $t$-tests and Kruskal-Wallis tests (KW) to quantify the significance of differences in our measurements among these populations. Spearman's rank correlation coefficients $(\rho)$ and Kendall rank correlation coefficients $\left(\tau_{\mathrm{B}}\right)$ provide measures of significance for correlations.

Our results reveal statistically significant differences between the 20 study reaches based on physiography (Fig. 2b). Reported TSS fluxes for rivers from the Andes-Foreland Basin are significantly greater than the fluxes for rivers of the Central Trough and shields ( $t$-tests: $\alpha<0.001$; KW: $\alpha<0.005$ ). The sediment-laden rivers of the Andes-Foreland Basin also experience the highest rates of meander migration and cutoff-rates significantly greater than those in rivers of the Central Trough and shields ( $t$-tests: $\alpha<0.001$; KW: $\alpha<0.001)$. Meander migration and cutoff rates for the study reaches positively correlate with estimates of TSS flux (Fig. 2c,d). The systematic differences observed here are not associated with differences in average channel gradient, at least within the uncertainties of available Shuttle Radar Topography Mission data (Supplementary Fig. 2), nor associated with differences in river discharge, which was accounted for through normalization by $R_{\mathrm{W}}$, which scales with bankfull discharge $\mathrm{e}^{22}$.

Although migration rates increase with TSS flux, channel sinuosity has been maintained within a small range owing to the corresponding increase in the frequency of cutoffs (Fig. 3a). Within the time period of investigation, sinuosity for 18 of the study reaches varied by only $\pm 6 \%$, with the sinuosity for the remaining two reaches reduced by roughly $17 \%$ owing to a temporal clustering of cutoffs (Fig. 3b). Maintenance of sinuosity through this mechanism results in floodplains of the rapidly migrating, sediment-laden rivers of the Andes-Foreland Basin being populated by the greatest density of open-water oxbow lakes among the sediment-source regions (Fig. 2b) ( $t$-tests: $\alpha<0.001$; KW: $\alpha<0.005$ ). Oxbow density also positively and significantly correlates with rates of meander migration and TSS flux (Fig. 3c).

The production of oxbow lakes by meander cutoff creates negative relief $^{23}$ or accommodation space for sediment storage in floodplains, important to the development of lentic (that is, relatively still water) sedimentary environments, landforms and ecosystems, as well as to the ability of floodplains to entrap carbon and pollutants in developed regions. If channel sinuosity $(T)$ is constant over time, then the rate of production of valley accommodation space $\left(S_{\mathrm{V}}\right)$ per channel width of down-valley distance $\left(\mathrm{ch}-\mathrm{w}^{3} \mathrm{yr}^{-1} \mathrm{ch}-\mathrm{w}^{-1}\right)$ is given by

$$
S_{\mathrm{V}}=C_{\mathrm{R}} L R_{\mathrm{W}} R_{\mathrm{D}}
$$

as long as a central tendency $(L)$ exists for oxbow lengths, and the bankfull width $\left(R_{\mathrm{W}}\right)$ and cross-sectionally averaged bankfull depth $\left(R_{\mathrm{D}}\right)$ of oxbows approximate those of the channel at the time of cutoff. Most of this accommodation space will be occupied by wash load in river environments where neck cutoff is commonplace and by variable amounts of bed material where chute cutoff occurs $^{24}$. Because the planform deformation of meanders is an important driver of the cutoff process, the role of the average annual rate of meander migration in determining $S_{\mathrm{V}}$ can be examined using the empirical relation identified here (Fig. 3a), where $C_{\mathrm{R}}$ is 

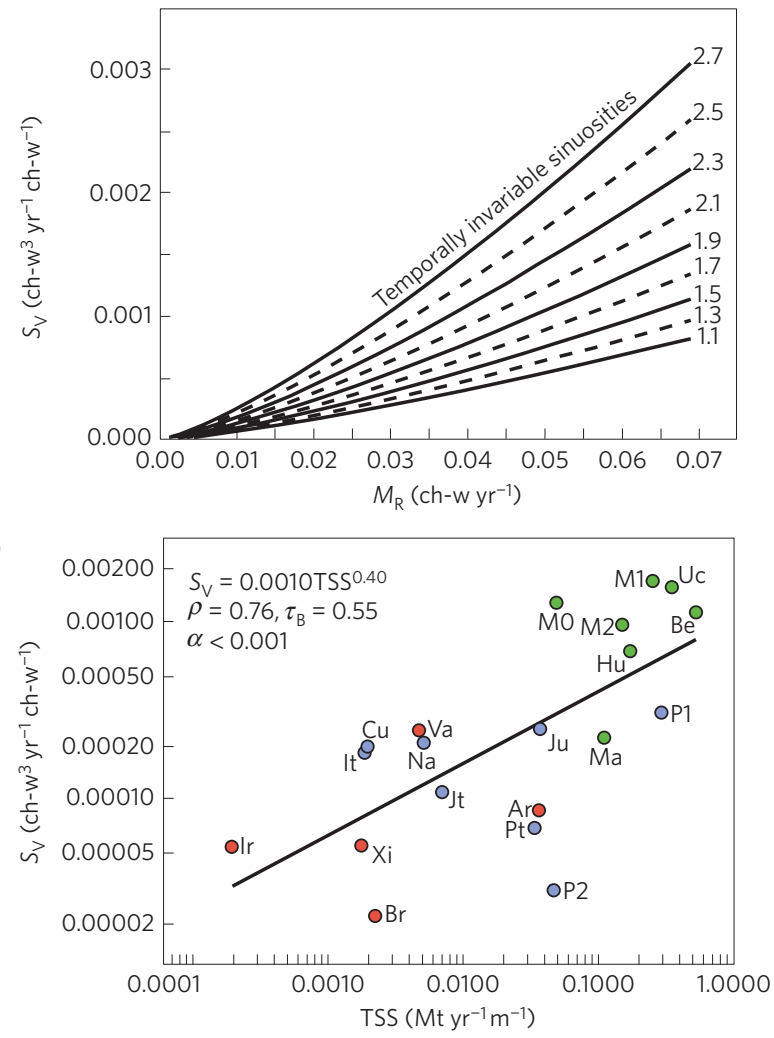

Figure 4 | Meander cutoff in the production of valley accommodation space for sediment storage. a, Average annual rate of production of valley accommodation space for sediment storage $\left(S_{V}\right)$ generated by meander cutoff (cubic channel widths per year per channel width of down-valley distance) plotted against average annual meander migration rates $\left(M_{R}\right.$; channel widths per year) of rivers with temporally invariable sinuosities. b, Predictions of $S_{V}$ plotted against reported values of total suspended sediment (TSS) flux (megatonnes per year per metre of channel width) for the 20 study reaches shown in Fig. 2a.

approximated as $0.07 M_{\mathrm{R}}^{1.29}$. A worldwide survey of 911 oxbows $^{25}$ observed that $L$ (in channel-width units) can be approximated as $3.0 \mathrm{e}^{0.82 T}$, and after approximating $R_{\mathrm{D}}$ as $0.05 R_{\mathrm{W}}$ based on observations ${ }^{26}$, solutions to equation (1) reveal the sensitivity of $S_{\mathrm{V}}$ to rates of meander migration and sinuosity (Fig. $4 \mathrm{a}$ ). $S_{\mathrm{V}}$ increases with migration rate because the river produces oxbows more rapidly while maintaining its gradient and channel length. $S_{\mathrm{V}}$ also increases with sinuosity because cutoffs on more sinuous channels produce longer oxbows that provide more space for storing sediment.

There is no indication of a secular trend in oxbow density, and so a steady state in $S_{\mathrm{V}}$ seems to develop over a sufficiently long period, defined in part by the time required for the removal of oxbows by meander migration and alluviation ${ }^{27,28}$. The important implication here is that externally imposed sediment supplies that promote bar building and meander migration lead to an increase in valley-wide sediment-storage potential due to the indirect consequence of increasing cutoff rates, as reflected by solutions to equation (1) for the 20 study reaches (Fig. 4b). Predictions of $S_{\mathrm{V}}$ positively correlate with TSS flux and are greatest within reaches of the Andes-Foreland Basin ( $t$-tests: $\alpha<0.001$; KW: $\alpha<0.005$; Supplementary Table 2). Oxbow alluviation can significantly enhance valley-wide sediment storage ${ }^{29,30}$, and our findings suggest that the addition of bed material to the channel should also increase the topographic and sedimentological complexity of the floodplain as a dynamic but steady-state planform develops and is maintained. The dynamism of the planforms within the sediment-rich rivers of the Andes-Foreland Basin indicates the great sensitivity of these river systems to the disruption of sediment supplies by large waterstorage reservoirs proposed for the Amazon Basin ${ }^{5}$.

\section{Methods}

We used geo-referenced Landsat images recorded between 1985 and 2013 (three to five per river) to digitize channel centrelines from points delineating vegetated bank lines at a spacing of approximately one channel width in the downstream direction. Average bankfull channel width was calculated from at least 15 measurements along straight channel segments between meanders using the most recent image available. Sequential images of a given reach yielded different centrelines, and intervals between crossings in two sequential centrelines define polygons from which minimum average annual migration rates were calculated ${ }^{18}$. The migration rates are minima because the direction of channel shift may have reversed for some portion of time between images. Sinuosity was calculated as the ratio of channel centreline length to the sum of the channel-belt axis lengths. Meander cutoffs were recorded between consecutive image dates, and the average annual meander cutoff rate was calculated as $($ no. +1$) / N$, where no. is the number of cutoff events observed and $N$ is the number of years between recorded images. This calculation is consistent with the fact that satellite records are of finite length, allowing only approximations to the true frequencies of counted events. The number of visible oxbows was tabulated from the most recent images, with oxbows recognized as arcuate open-water bodies. Details of the TSS flux estimates can be found in the Supplementary Information.

Received 23 May 2014; accepted 3 October 2014; published online 2 November 2014

\section{References}

1. Pittaluga, M. B. \& Seminara, G. Nonlinearity and unsteadiness in river meandering: A review of progress in theory and modelling. Earth Surf. Process. Landf. 36, 20-38 (2011).

2. Asahi, K., Shimizu, Y., Nelson, J. \& Parker, G. Numerical simulation of river meandering with self-evolving banks. J. Geophys. Res. 118, 2208-2229 (2013).

3. Dunne, T., Mertes, L. A. K., Meade, R. H., Richey, J. E. \& Forsberg, B. R. Exchanges of sediment between the flood plain and channel of the Amazon River in Brazil. Geol. Soc. Am. Bull. 110, 450-467 (1998).

4. Engel, F. L. \& Rhoads, B. L. Interaction among mean flow, turbulence, bed morphology, bank failures and channel planform in an evolving compound meander loop. Geomorphology 163-164, 70-83 (2012).

5. Finer, M. \& Jenkins, C. N. Proliferation of hydroelectric dams in the Andean Amazon and implications for Andes-Amazon connectivity. PLoS ONE 7, e35126 (2012)

6. Baker, V. R. Fluvial Sedimentology-Modern Rivers: Geomorphology and Sedimentology Vol. 5, 211-230 (Can. Soc. Petrol. Geol., 1977)

7. Filizola, N. \& Guyot, J. L. Suspended sediment yields in the Amazon basin: An assessment using the Brazilian national data set. Hydrol. Process. 23, 3207-3215 (2009)

8. Guyot, J. L. et al. Proc. 4th Int. Symp. River Sedimentation (International Network on Erosion and Sedimentation, 1989).

9. Latrubesse, E. M., Stevaux, J. C. \& Sinha, R. Tropical rivers. Geomorphology 70, 187-206 (2005)

10. Guyot, J. L., Bourges, J. \& Cortez, J. Variability in Stream Erosion and Sediment Transport Vol. 224, 223-231 (IAHS Publ., 1994).

11. Callander, R. A. Instability and river channels. J. Fluid Mech. 36, 465-480 (1969)

12. Gorycki, M. A. Hydraulic drag: A meander-initiating mechanism. Bull. Geol. Soc. Am. 84, 175-186 (1973).

13. Ikeda, S., Parker, G. \& Sawai, K. Bend theory of river meanders. Part 1. Linear development. J. Fluid Mech. 112, 363-377 (1981).

14. Van de Lageweg, W. I., van Dijk, W. M., Baar, A. W., Rutten, J. \& Kleinhans, M. G. Bank pull or bar push: What drives scroll-bar formation on meandering rivers. Geology 42, 319-322 (2014).

15. Dietrich, W. E., Smith, J. D. \& Dunne, T. Flow and sediment transport in a sand bedded meander. J. Geol. 87, 305-315 (1979).

16. Lewin, J. Initiation of bed forms and meanders in coarse-grained sediment. Geol. Soc. Am. Bull. 87, 281-285 (1976).

17. Braudrick, C. A., Dietrich, W. E., Leverich, G. T. \& Sklar, L. Experimental evidence for the conditions necessary to sustain meandering in coarse-bedded rivers. Proc. Natl Acad. Sci. USA 106, 16936-16941 (2009).

18. Constantine, C. R. Quantifying the Connections Between Flow, Bar Deposition, and Meander Migration in Large Gravel-Bed Rivers $\mathrm{PhD}$ thesis, Univ. California (2006).

19. Pizzuto, J. E. \& Meckelnburg, T. S. Evaluation of a linear bank erosion equation. Wat. Resour. Res. 25, 1005-1013 (1989). 
20. Legleiter, C. J., Harrison, L. R. \& Dunne, T. Effect of point bar development on the local force balance governing flow in a simple, meandering gravel-bed river. J. Geophys. Res. 116, http://dx.doi.org/10.1029/2010JF001838 (2011).

21. Latrubesse, E. M., Amsler, M. L., de Morais, R. P. \& Aquino, S. The geomorphologic response of a large pristine alluvial river to tremendous deforestation in the South American tropics: The case of the Araguaia River. Geomorphology 113, 239-252 (2009).

22. Beighley, R. E. \& Gummadi, V. Developing channel and floodplain dimensions with limited data: A case study in the Amazon Basin. Earth Surf. Process. Landf. 36, 1059-1071 (2011).

23. Lewin, J. \& Ashworth, P. J. The negative relief of large river floodplains. Earth Sci. Rev. 129, 1-23 (2014)

24. Constantine, J. A., Dunne, T., Piégay, H. \& Kondolf, M. Controls on the alluviation of oxbow lakes by bed-material load along the Sacramento River, California. Sedimentology 57, 389-407 (2010).

25. Constantine, J. A. \& Dunne, T. Meander cutoff and the controls on the production of oxbow lakes. Geology 36, 23-26 (2008).

26. Mertes, L. A. K., Dunne, T. \& Martinelli, L. A. Channel-floodplain geomorphology along the Solimões-Amazon River, Brazil. Geol. Soc. Am. Bull. 108, 1089-1107 (1996).

27. Lauer, J. W. \& Parker, G. Net local removal of floodplain sediment by river migration. Geomorphology 96, 123-149 (2008).

28. Aalto, R., Lauer, J. W. \& Dietrich, W. E. Spatial and temporal dynamics of sediment accumulation and exchange along Strickland River floodplains (Papua New Guinea) over decadal-to-centennial timescales. J. Geophys. Res 113, http://dx.doi.org/10.1029/2006JF000627 (2008).

29. Räsänen, M., Neller, R., Salo, J. \& Jungner, H. Recent and ancient fluvial deposition systems in the Amazonian foreland basin, Peru. Geol. Mag. 129, 293-306 (1992)
30. Miller, J. et al. Effects of the 1997 flood on the transport and storage of sediment and mercury within the Carson River Valley, West-Central Nevada. J. Geol. 107, 313-327 (1999).

\section{Acknowledgements}

The study was supported by NERC grant NE/I002081/1, NASA grant NAG5-6120, the Don J. Easterbrook Award of the Geological Society of America, and by the National Research Foundation Singapore and the Singapore Ministry of Education under the Research Centres of Excellence initiative (EOS contribution 78). The UK Leverhulme Trust, the US Fulbright Commission, and the Earth Observatory of Singapore also supported T. Dunne. We thank N. Morales, J. Teng and C. Constantine for assistance in data collection and for discussions relating to hypothesis development.

\section{Author contributions}

J.A.C. and T.D. conceived the study. J.A. conducted calculations of channel change, and T.D., J.A.C. and J.A. compiled data on sediment loads. C.L. provided technical expertise in analysing channel change from remote sensing data. J.A.C. and T.D. led data analysis and interpretation, assisted by all co-authors. J.A.C. drafted the paper, which was then reviewed by all co-authors.

\section{Additional information}

Supplementary information is available in the online version of the paper. Reprints and permissions information is available online at www.nature.com/reprints.

Correspondence and requests for materials should be addressed to J.A.C. or T.D.

\section{Competing financial interests}

The authors declare no competing financial interests. 